\title{
Particle shape factors and fractal dimension after large shear strains in carbonate sand
}

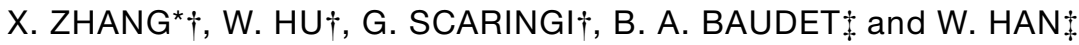

\begin{abstract}
Changes of grain shape and breakage under compression and shearing can affect the mechanical properties of granular soils. In this work, a parametric study was performed through ring-shear tests on carbonate sand, under $\sigma_{\mathrm{n}}=600 \mathrm{kPa}$ and $v=6 \mathrm{~mm} / \mathrm{min}$, to evaluate the evolution of particle breakage, fractal dimension and particle shape with the shear strain. Breakage mostly occurred for $\gamma \leq 4000 \%$, with a consequent increase in fractal dimension. Under larger strains, only negligible breakage occurred, while the particles became more rounded, and the fractal dimension increased only slightly. Interestingly, the shape factors also tend towards similar values for particles of any size larger than $0.063 \mathrm{~mm}$ after large shearing. This indicates that these particles tend towards a self-similar form - and hence scale invariance - when the grading reaches a fractal particle size distribution. Some tests were also performed on soils with different median size and coefficient of uniformity, which showed that larger particles and poorly graded soils are more prone to breakage, and are closer to a fractal distribution after shearing. Conversely, the final particle shape did not seem to be affected by grading and size significantly.
\end{abstract}

KEYWORDS: fractals; particle breakage; ring shear tests

ICE Publishing: all rights reserved

\section{NOTATION}

$A$ area of the particle's image

AR aspect ratio

$B_{\mathrm{r}} \quad$ relative breakage

$C_{\mathrm{u}}$ coefficient of uniformity

Cx convexity

$D$ fractal dimension

$d$ particle size

$d_{x}$ sieve size through which $x \%$ of the particles by weight will pass

$d_{50}$ median particle size

$P$ perimeter of the particle's image

$S^{Q P} \quad$ sphericity

$s$ shearing distance

$v$ shear velocity

$\gamma$ shear strain

$\sigma_{\mathrm{n}}$ normal stress

\section{INTRODUCTION}

Soil grains can undergo extensive crushing due to compressive and shear stresses (e.g. Miura \& O-Hara, 1979; Hagerty et al., 1993). Fragmentation can affect the material properties and can play a role, for instance, in the long runout of rock avalanches (Taboada \& Estrada, 2009; De Blasio \& Crosta, 2015) and in their potential to generate debris flows (Caballero et al., 2014; Hu et al., 2017a).

Particle crushing increases with particle angularity and the median particle size in one-dimensional compression

Manuscript received 7 November 2017; first decision 25 February 2018; accepted 17 March 2018.

Published online at www.geotechniqueletters.com on 16 April 2018.

*School of Mechanics and Civil Engineering, China University of Mining and Technology, Beijing, People's Republic of China.

† State Key Laboratory of Geohazard Prevention and Geoenvironment Protection, Chengdu University of Technology, Chengdu, People's Republic of China.

Department of Civil, Environmental and Geomatic Engineering, University College London, London, UK. tests (Hagerty et al., 1993). An ultimate grading - possibly dependent on stress history (Miao \& Airey, 2015) - is thought to exist under very large compression (Hagerty et al., 1993). Experimental studies suggest the existence of an ultimate grading after large shear strains as well (Coop et al., 2004), which depends on normal stress and initial grading.

The grading of many products of weathering or fragmentation follows a power law (Turcotte, 1986), creating fractal sets (Mandelbrot, 1982). The fractal dimension, $D$, is used to characterise ultimate grading in constitutive models (Bolton \& McDowell, 1997; Gajo \& Muir Wood, 1999; Muir Wood, 2007; Einav, 2007a, 2007b; Yao et al., 2008, 2009; Altuhafi et al., 2010). It can be estimated from the mass-size distribution or from the number-size distribution (Perfect et al., 1992; Hooke \& Iverson, 1995; Altuhafi \& Baudet, 2011). For fractal distribution, the slope of the cumulative mass distribution against the particle size in a $\log -\log$ plot is equal to $3 D$ (Perfect et al., 1992; Rasiah et al., 1993). Independent of the initial distribution, most granular soils tend to $D \approx 2 \cdot 5$ under compression only (Turcotte, 1986; Perfect et al., 1992; McDowell et al., 1996). For carbonate sand, Coop et al. (2004) evaluated an ultimate $D=2.57$ after compression and large shear strains. Miao \& Airey (2013) found that two distinct values of $D$ can be evaluated for carbonate sand over two size ranges (pseudo-fractal distribution, Huang \& Bradford, 1992), with a threshold of around $75 \mu \mathrm{m}$ for uniform and fractal gradings. Zhang \& Baudet (2014) also observed that a single $D$ cannot be obtained for gap-graded soils after large strains.

Although several works focused on changes of particle size distribution due to compression and shearing, changes of shape factors were often overlooked, even though they can affect the soil behaviour significantly (e.g. Santamarina \& Cho, 2004; Cho et al., 2006; Rousé et al., 2008; Cavarretta et al., 2010). The particle shape can be described by shape factors, such as sphericity, convexity and aspect ratio (Wadell, 1932; Krumbein \& Sloss, 1951). The shape can affect various physical and mechanical parameters, such as small strain and large strain stiffness 
(Santamarina \& Cho, 2004; Cho et al., 2006). The critical state friction angle increases with angularity (Santamarina \& Cho, 2004; Cavarretta et al., 2010). Maximum and minimum void ratios (Cubrinovski \& Ishihara, 2002; Rousé et al., 2008) and packing density (Cho et al., 2006) also depend on angularity. The shape factors can be quantified through digital photography and microscopy (Santamarina \& Cho, 2004; Cho et al., 2006; Clayton et al., 2006; Rousé et al., 2008). Dynamic laser image analysers are becoming increasingly popular to scan large sets of randomly oriented particles in short time (Fonseca \& O'Sullivan, 2008; Cavarretta et al., 2010; Altuhafi \& Baudet, 2011; Altuhafi \& Coop, 2011). In this paper, such changes are shown and analysed to illustrate the characteristics of self-similarity and scale invariance comprehensively for the soil fraction larger than $63 \mu \mathrm{m}$ (e.g. Miao \& Airey, 2013; Zhang \& Baudet, 2014). The shear strain-dependent changes of particle shape were investigated through ring-shear tests and were compared with changes of particle size, breakage and fractal dimension.

\section{MATERIALS AND METHODS}

A typical carbonate sand from the South China Sea was used in this work. It is composed of corals, molluscs shells and algal sediments. A typical scanning electron microscopy (SEM) image of the grains before shearing is shown in Fig. 1(a). The mineral composition was evaluated using an energy dispersive spectroscopy system on a Hitachi S3400N SEM apparatus. Calcium carbonate accounts for more than $98 \%$ of the total weight, with negligible amounts of other minerals. Samples with different median size $\left(d_{50}\right)$ and

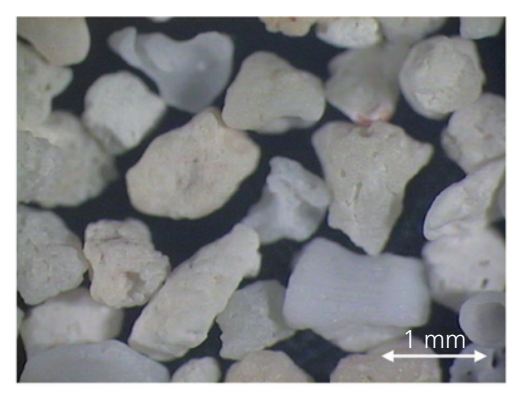

(a)

\begin{tabular}{|c|c|c|c|}
\hline $\begin{array}{l}\text { Feret_min } \\
\text { Sphericity } \\
\text { Aspect ratio } \\
\text { Convexity } \\
\text { Image number }\end{array}$ & $\begin{array}{r}719.871 \\
0.722 \\
0.376 \\
0.911 \\
r \quad 5785\end{array}$ & $\begin{array}{l}\text { Feret_min } \\
\text { Sphericity } \\
\text { Aspect ratio } \\
\text { Convexity } \\
\text { Image number }\end{array}$ & $\begin{array}{r}705 \cdot 630 \\
0.806 \\
0.419 \\
0.969 \\
1143\end{array}$ \\
\hline $\begin{array}{l}\text { Feret_min } \\
\text { Sphericity } \\
\text { Aspect ratio } \\
\text { Convexity } \\
\text { Image number }\end{array}$ & $\begin{array}{r}751.130 \\
0.800 \\
0.549 \\
0.912 \\
5319\end{array}$ & $\begin{array}{l}\text { Feret_min } \\
\text { Sphericity } \\
\text { Aspect ratio } \\
\text { Convexity } \\
\text { Image number }\end{array}$ & $\begin{array}{r}789.990 \\
0.846 \\
0.611 \\
0.945 \\
2125\end{array}$ \\
\hline $\begin{array}{l}\text { Feret_min } \\
\text { Sphericity } \\
\text { Aspect ratio } \\
\text { Convexity } \\
\text { Image number }\end{array}$ & $\begin{array}{r}820.018 \\
0.898 \\
0.719 \\
0.964 \\
7331\end{array}$ & $\begin{array}{l}\text { Feret_min } \\
\text { Sphericity } \\
\text { Aspect ratio } \\
\text { Convexity } \\
\text { Image number }\end{array}$ & $\begin{array}{r}852 \cdot 107 \\
0.862 \\
0.815 \\
0.938 \\
5365\end{array}$ \\
\hline
\end{tabular}

(b)

Fig. 1. (a) SEM image of the tested sand before shearing; (b) images of sand grains obtained with QicPic with aspect ratios ranging from 0.3 to $0 \cdot 8$. The unit of the Feret-min is $\mu \mathrm{m}$ coefficient of uniformity $\left(C_{\mathrm{u}}=d_{60} / d_{10}\right)$ were prepared for the tests. The particle size $d$ was assumed equal to the particle's minimum Feret diameter, measured by a dynamic laser image analyser (QicPic apparatus). Feret minimum is the minimum distance between two parallel lines between opposite sides of a particle in a two-dimensional image. The Feret minimum distribution was shown to correspond to particle size distribution obtained by mechanical sieving by Altuhafi \& Coop (2011) and Altuhafi et al. (2013).

The tests were performed in a commercial IC-NGI-type (Bishop et al., 1971) ring-shear apparatus (Wille Geotechnik $\mathrm{GmbH}$ ) with stress-strain servo-control and automatic data acquisition. Specimens with $100 \mathrm{~mm}$ outer diameter, $50 \mathrm{~mm}$ inner diameter and $25 \mathrm{~mm}$ thickness were used. The shear strain $\gamma$ was defined as the ratio between the shearing distance $s$ and the initial specimen's height.

The specimens were tested under water-saturated conditions, consolidated under $\sigma_{\mathrm{n}}=600 \mathrm{kPa}$. The stress value $(600 \mathrm{kPa})$ was chosen arbitrarily, to achieve crushing after a suitable time/shearing distance. Shear rate is set to $v=6 \mathrm{~mm} / \mathrm{min}$. This shear rate should not produce any significant pore pressure excess in the testing conditions (e.g. Okada et al., 2004; Scaringi et al., 2017; Hu et al., 2017b). Rate effects on the available strength are negligible in sands, given their comparatively high permeability, and are generally small $(<10 \%)$ for any soil for $v<10 \mathrm{~mm} / \mathrm{min}$ (e.g. Tika et al., 1996; Carrubba \& Colonna, 2006; Saito et al., 2006, 2007; Scaringi et al., 2013, 2017; Hu et al., 2017a, 2017b). Okada et al. (2004), which referred to crushable particles, in particular, did not find significant pore pressure excess in tests carried out under the same shear rate as in this study. Thus, the authors are quite confident that their results are not significantly affected by excess pore pressures. The specimens were prepared through the moist tamping method: the particles were evenly divided by weight and tamped in several successive layers. The prepared specimens were submerged in water. Trapped air bubbles were extracted through vacuum pumping for about $2 \mathrm{~h}$, until no more air extraction was observed. In this way, full (or very close to full) saturated condition could be achieved. Eleven tests were performed on specimens with the same $d_{50}$ $(1.07 \mathrm{~mm})$ and $C_{\mathrm{u}}(1.3)$, sheared over different distances from $0 \cdot 1$ to $25 \mathrm{~m}$. Six tests were performed on specimens with different $d_{50}(0.39,0.54,0.77,1.07,1.38,1.80 \mathrm{~mm})$ but with the same $C_{\mathrm{u}}(1 \cdot 3)$, sheared over the same distance, $s=2 \mathrm{~m}$. Finally, three tests were performed on specimens with different $d_{50}(0.90,0.98,1.07 \mathrm{~mm})$ and $C_{\mathrm{u}}(1.3,1 \cdot 85$, $2 \cdot 60)$ but with the same $d_{90}(1.18 \mathrm{~mm})$, sheared over the same distance, $s=2 \mathrm{~m}$.

The particle shape factors were measured by the QicPic apparatus. QicPic includes a GRADIS system (i.e. 'gentle dispersion in free fall') for dry particles and a LIXELL system (i.e. 'ultraflexible wet dispersion for disperse systems in open or closed loops') for wet particles. The GRADIS system with a Camera M7 was used in this work, which has a good shape recognition range from 90 to $3410 \mu \mathrm{m}$, and a good size recognition range from 10 to $10240 \mu \mathrm{m}$. The aspect ratio, $\mathrm{AR}$, is the ratio between the minimum and the maximum Feret diameters. The convexity, $\mathrm{Cx}$, is the ratio between the area of the imaged particle, $A$, and the area of its convex envelope. The sphericity, $S^{Q P}$, is equal to $2 \sqrt{\pi A} / P$, where $P$ is the perimeter of the imaged particle. Figure 1(b) gives an example of aspect ratios, approximately ranging from $0 \cdot 3$ to $0 \cdot 8$. To evaluate the breakage quantitatively, the total breakage, the breakage potential and the relative breakage $\left(B_{\mathrm{r}}\right)$ were obtained following Hardin (1985). The total breakage is the area between the initial and final grading curves; the breakage potential is the total breakage calculated assuming all particles had broken into fragments 
smaller than $0.063 \mathrm{~mm} ; B_{\mathrm{r}}$ is the ratio between total breakage and breakage potential.

\section{RESULTS}

\section{Effect of shear strain}

Figure 2(a) shows the changes of particle size after shearing up to $s=25 \mathrm{~m}$ for specimens with the same initial grading $\left(d_{50}=1.07 \mathrm{~mm}, C_{\mathrm{u}}=1 \cdot 3\right)$. Most of the crushing occurred while $s \leq 1 \mathrm{~m}$. The proportion of particles finer than $0.063 \mathrm{~mm}$ and $B_{\mathrm{r}}$ are shown in Fig. 2(b) against $s$, and are compared with $D$ obtained for the same specimens. It can be seen that $B_{\mathrm{r}}$ and $D$ exhibit a similar tendency to increase with $s$, and most of the variation occurs while $s \leq 1 \mathrm{~m}$. (i.e. $\gamma \leq 4000 \%$ ). It should be noted that the fractal dimension is calculated from the slope of particle size distribution between size $0.063 \mathrm{~mm}$ and size of the largest particle because there is a knee at size of $0.063 \mathrm{~mm}$ (Zhang \& Baudet, 2014). Miao \& Airey (2013) also stated that two fractal dimensions could be found in particle size distribution curve from a size range of 0.063 to $2.36 \mathrm{~mm}$. Coop et al. (2004) also suggested that the final grading is reached after shear strains of the same magnitude, with an ultimate $D=2 \cdot 57$. In this work, an ultimate $D=2.56$ was obtained.

Figure 3 shows the evolution of AR, Cx and $S^{Q P}$ with $s$. They all slightly increase with the shearing distance as the

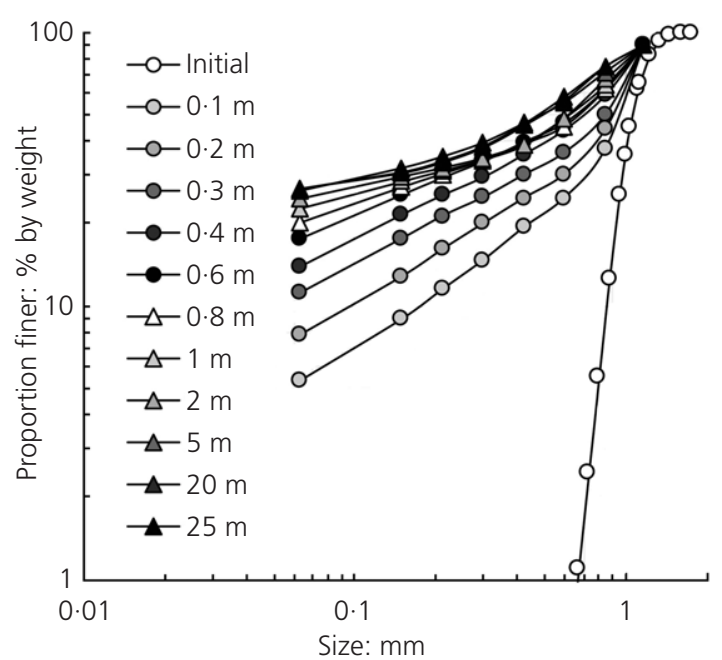

(a)

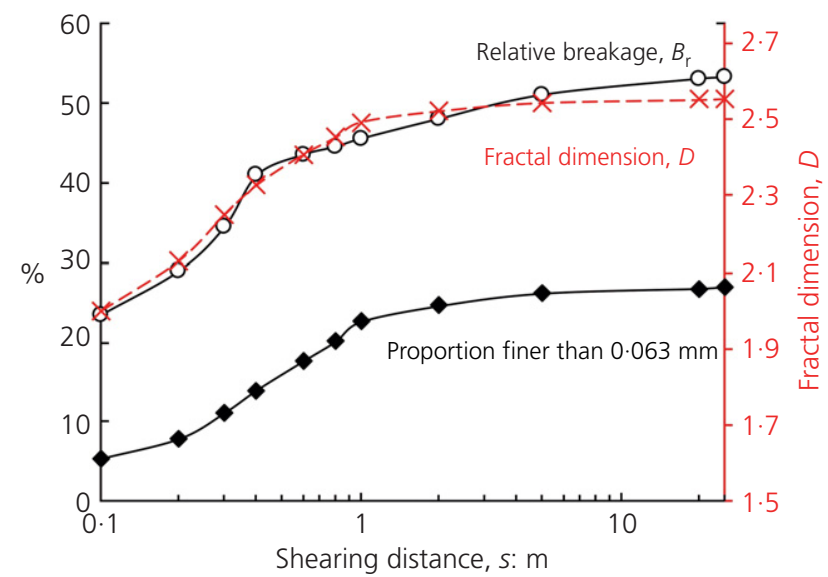

(b)

Fig. 2. (a) Soil grading after shearing over different distances; (b) proportion finer than $0.063 \mathrm{~mm}$, relative breakage $B_{\mathrm{r}}$ and fractal dimension $D$ against the shearing distance $s$ particles tend to become smoother and more rounded. Again, most of the variation occurs while $s \leq 1 \mathrm{~m}$. However, it is worth noting that $\mathrm{Cx}$ of the particles generated by crushing is smaller than that of the parent, coarser particles, while their $S^{Q P}$ is higher. This tendency is opposite to what is found by Altuhafi \& Coop (2011) on uniform sand after

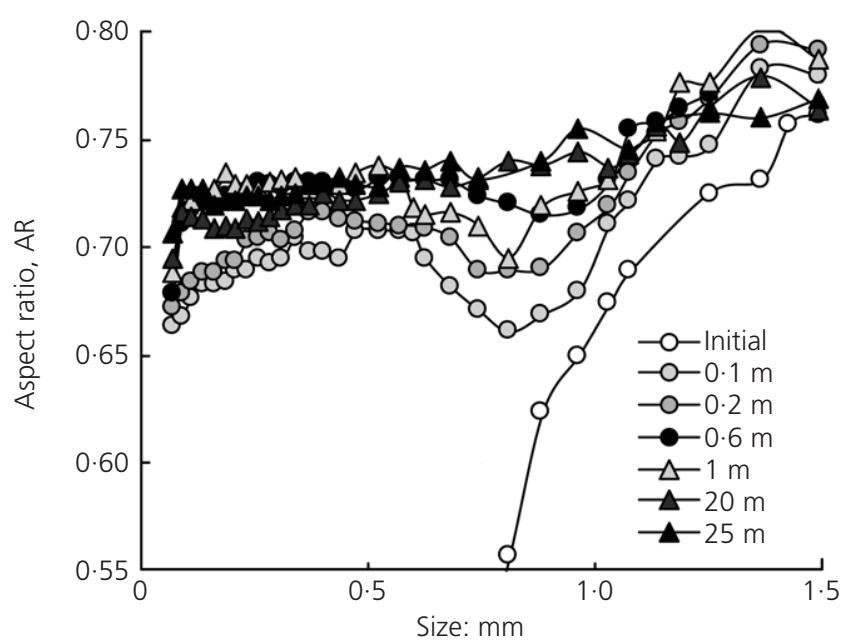

(a)

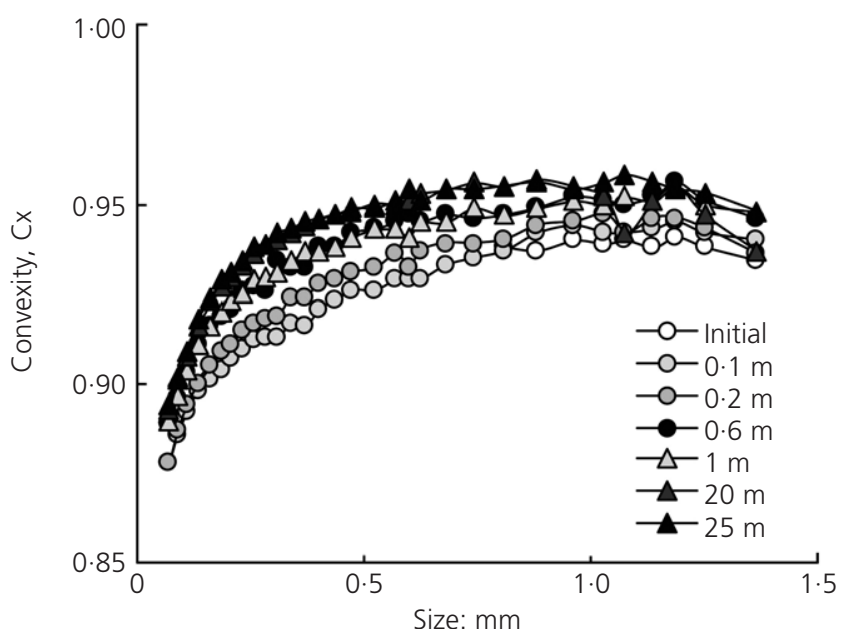

(b)

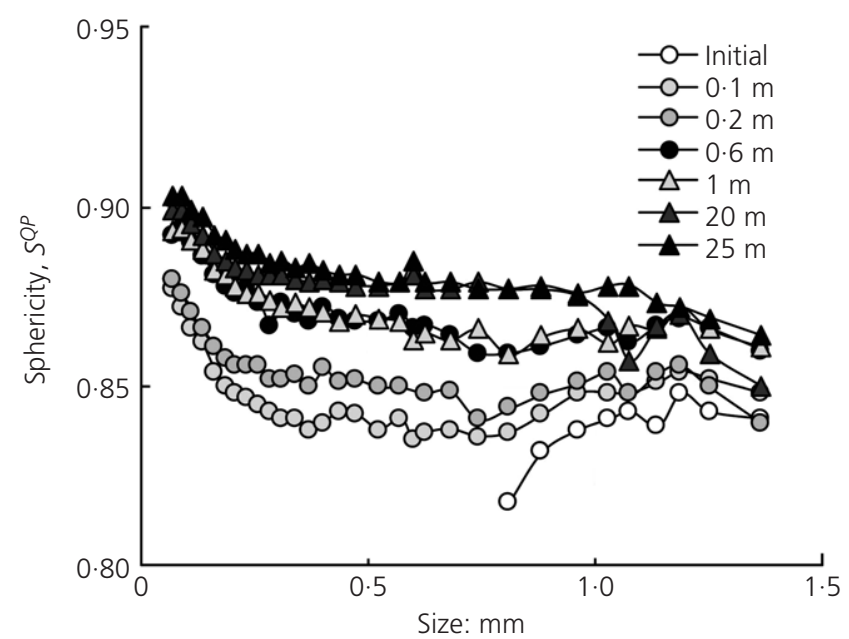

(c)

Fig. 3. The relationship between shape factors and particle size after shearing over distances from $0 \cdot 1$ to $25 \mathrm{~m}$ : (a) aspect ratio, (b) convexity, (c) sphericity. Only selected results are shown for clarity 
one-dimensional compression under $\sigma_{\mathrm{n}}=30 \mathrm{MPa}$, possibly because their material was initially more rounded and contained less asperities. Conversely, Zhang \& Baudet (2013) did not find significant changes of shape factors after compression up to $\sigma_{\mathrm{n}}=31 \mathrm{MPa}$ of gap-graded granite grains, possibly due to the negligible abrasion, which, instead, is significant during shearing.

Although the soil after shearing tends to be well graded, its cumulative mass-size distribution is not linear over the whole size range. Thus, a representation as in Fig. 3, with the particle size as the independent variable, might be misleading. An alternative representation is shown in Fig. 4. A point on the curve represents the percentage of particles by mass with a shape factor lower than a given value. With $s$ increasing, the curves representing AR slightly shift downwards, becoming steeper, reflecting that there are fewer particles with low AR, and comparatively more particles with high AR (Fig. 4(a)). The same observation can be made

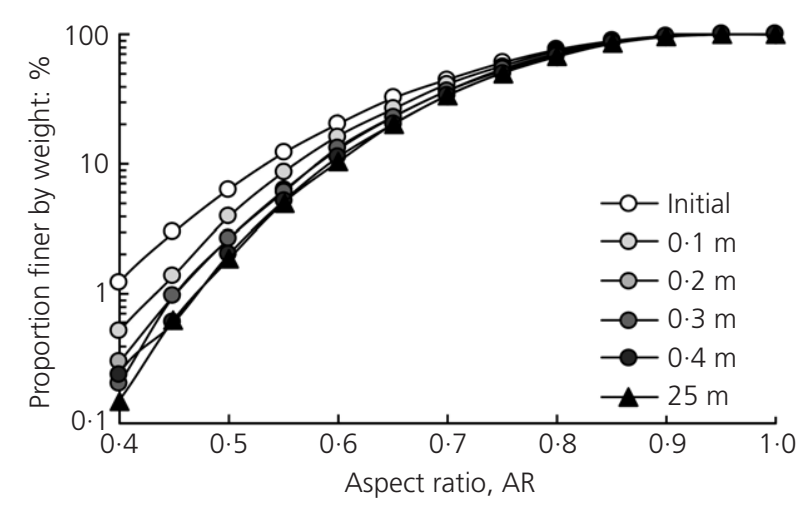

(a)

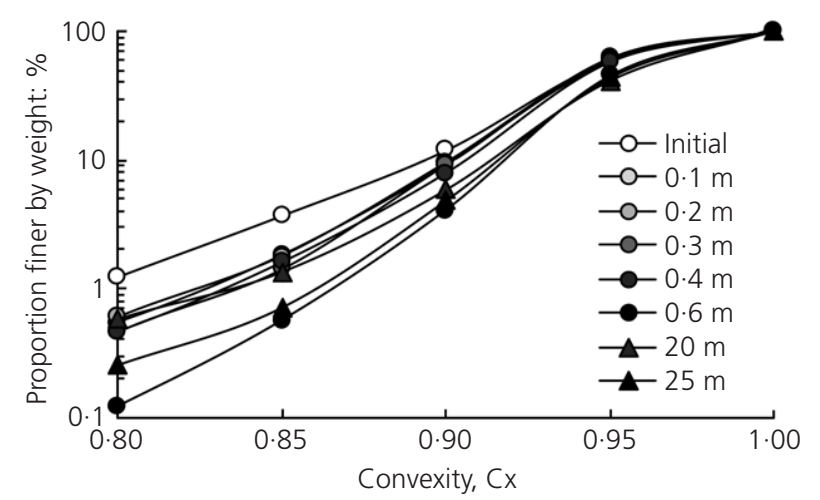

(b)

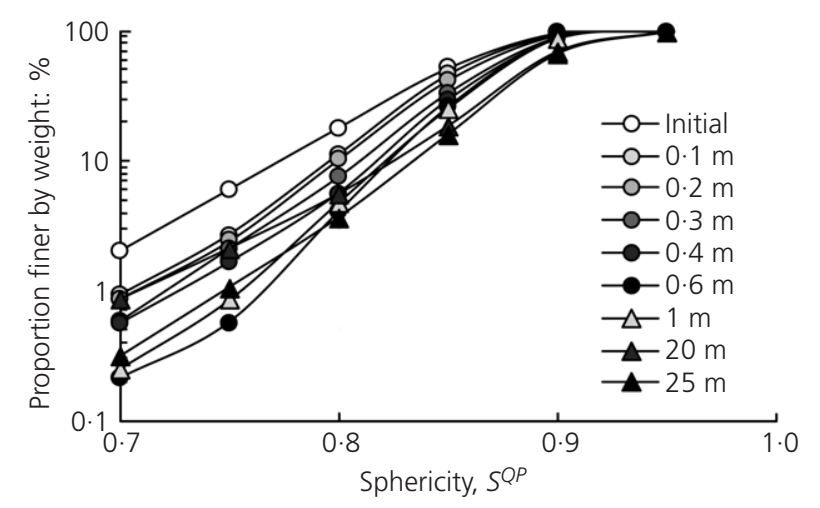

(c)

Fig. 4. The relationship between shape factors and cumulative mass-size distribution after shearing over distances from 0.1 to $25 \mathrm{~m}$ : (a) aspect ratio, (b) convexity, (c) sphericity. Only selected results are shown for clarity for Cx and $S^{Q P}$ (Figs 4(b) and 4(c)) which, in addition, tend to linearise, meaning that the shape factor distribution tends to be self-similar (i.e. fractal). Similar tests were also conducted on completely decomposed granite (e.g. Zhang $\&$ Baudet, 2013). This kind of grains is widely distributed in Hong Kong and China. Consistent results were found in this work, suggesting that the findings are not limited to a specific tested material.

\section{Effect of particle size}

Figure 5(a) shows the particle size distribution of specimens with different initial grading $\left(0.39 \leq d_{50} \leq 1.80 \mathrm{~mm}\right.$, $C_{\mathrm{u}}=1 \cdot 3$ ) after shearing up to $s=2 \mathrm{~m}$. The proportion of particles with $d \leq 0.063 \mathrm{~mm}$ generated during shearing increases with $d_{50}$ increasing, and the larger the initial $d_{50}$,

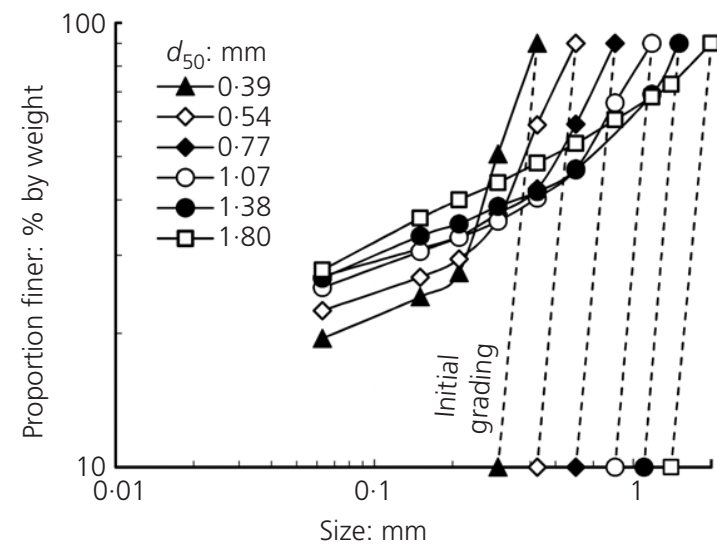

(a)

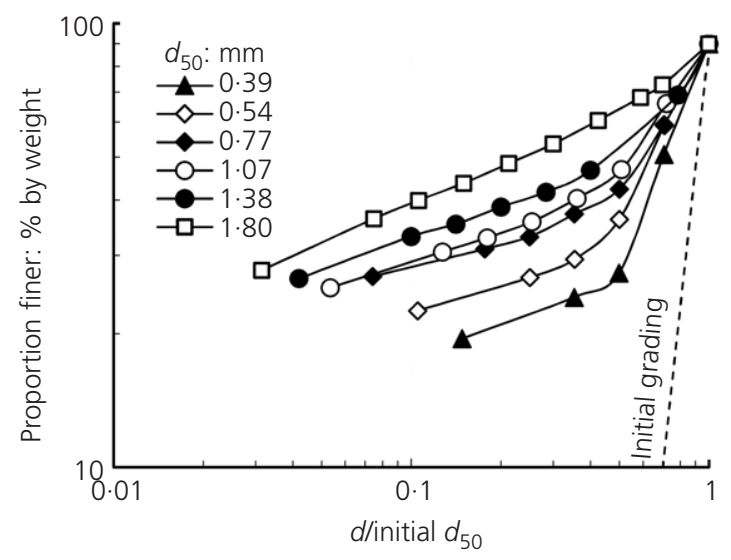

(b)

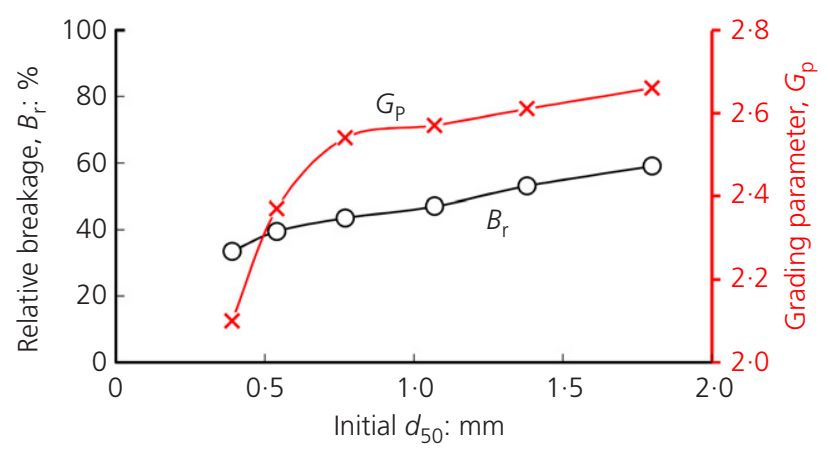

(c)

Fig. 5. (a) Grain size distribution of specimens with different initial grading (dashed curves) after shearing for $s=2 \mathrm{~m}$; (b) curves normalised by the initial $d_{50}$; (c) relative breakage $B_{\mathrm{r}}$ and fractal dimension $D$ of the specimens after shearing 
the better the grain size curve approximates a fractal distribution (i.e. it tends to be linear in a $\log -\log$ plot). In Fig. 5(b), the same curves are normalised by their initial $d_{50}$ to better highlight the relative changes in grain size. It is interesting to note that the curves shown in Fig. 5(b) (same shearing distance, increasing initial grain size) resemble the curves shown in Fig. 2(a) (same initial grading, increasing shearing distance). This indicated that breakage is gradually increasing with the increase of initial $d_{50}$ due to the average tensile strength that decreases with increasing size of particles (McDowell \& Amon, 2000). Muir Wood (2007) suggested that the slope of the particle size distribution could be using a parameter grading parameter $G_{\mathrm{P}}$ instead of fractal dimension, and only the particle size distribution reaches the ultimate grading that the value of $G_{\mathrm{P}}$ is equal to the fractal dimension. Finally, Fig. 5(c) shows $B_{\mathrm{r}}$ and $G_{\mathrm{P}}$ of the various specimens after shearing to the same distance under the same vertical stress. With the initial $d_{50}$ increasing, the relative breakage increases and so does the fractal dimension. Larger particles are more likely to contain imperfections or cracks, so their average tensile strength is generally comparatively smaller than that of smaller particles (Nakata et al., 1999; McDowell, 2002; McDowell \& De Bono, 2013). However, Tsoungui et al. (1999) suggested that large particles could be cushioned by the smaller particles resulting in smaller particles suffering more breakage in experimental or numerical tests. This is argued by McDowell \& De Bono (2013) that large particles could suffer breakage when the smaller particle reaches the comminution limit. Furthermore, McDowell (2002) found that the yielding stress of specimens with different initial grain sizes is different; hence, particles with different sizes could suffer different breakage under the same stress.

Figure 6 shows the relationship between the shape factors and the particle size. The values of AR, Cx and $S^{Q P}$ of the sheared specimens are slightly higher than those of the initial ones. No clear dependency of the shape factors to the initial grain size can be seen. However, the specimen with initially larger particles $\left(d_{50}=1.38 \mathrm{~mm}\right)$ is characterised by slightly lower values of the shape factors after shearing compared with those of the specimens with smaller particles, possibly due to the larger relative breakage (Fig. 5(c)), which resulted in a larger number of angular particles being produced.

\section{Effect of grading}

Figure 7 shows the particle size distribution of specimens with different initial $d_{50}$ and $C_{\mathrm{u}}$, but with the same $d_{90}$, after shearing for $s=2 \mathrm{~m}(\gamma=8000 \%)$. Breakage seems to increase with the increase in $C_{\mathrm{u}}$, but the distribution of fine particles $(d \leq 0.3 \mathrm{~mm})$ is practically the same for all specimens. The result is consistent with the findings of Nakata et al. (2001), who observed that well-graded soils suffer less breakage than uniform soils. This might be due to the higher coordination number and, consequently, the smaller intergranular forces acting in well-graded soils compared with uniform soils. However, uniform soils have larger breaking potential than well-graded soils. Thus, if computing $B_{\mathrm{r}}$ for the specimens shown in Fig. 7, values very close to each other can be found $(0 \cdot 42-0 \cdot 44)$, and the resulting fractal dimension is practically the same $(D \approx 2 \cdot 58)$.

\section{CONCLUSIONS}

Most of particle crushing occurred for shearing distances of up to $1 \mathrm{~m}(\gamma \leq 4000 \%)$ in uniform soil specimens $\left(C_{\mathrm{u}}=1 \cdot 3\right)$ under $\sigma_{\mathrm{n}}=600 \mathrm{kPa}$. A good agreement was seen between the trends of relative breakage and fractal dimension against the shearing distance, with the grain size distribution tending towards a fractal distribution after large displacements. The shape factors increased slightly with the shearing distance, as the particles tended to become rounder. Particles generated by crushing had similar or slightly higher values of shape factors compared with those of the parent particles. Hence, the shape factors seem to tend towards a fractal distribution too. Uniform soil specimens with increasing size showed increasing relative breakage and fractal dimension after the same shearing distance, and a better graded final grading, which more closely resembled a fractal distribution. On the other hand, the final shape factor distributions did not

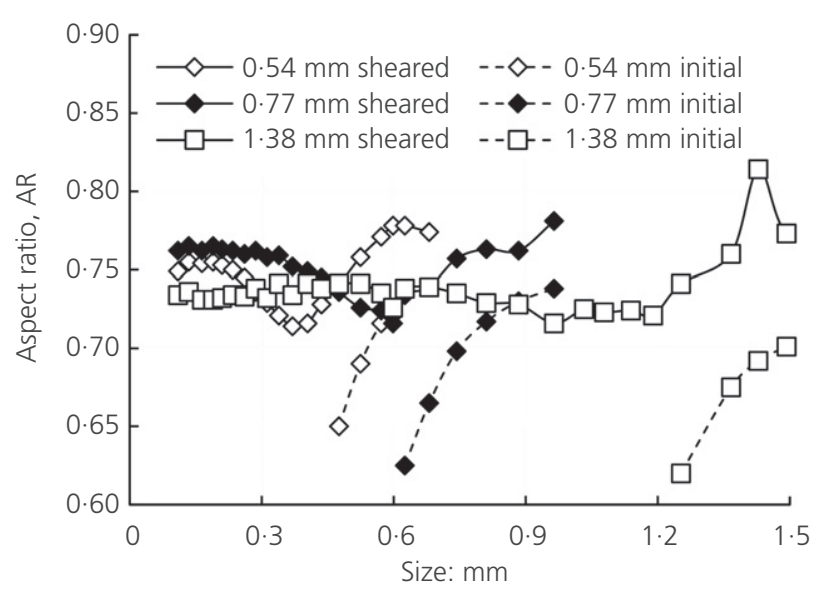

(a)

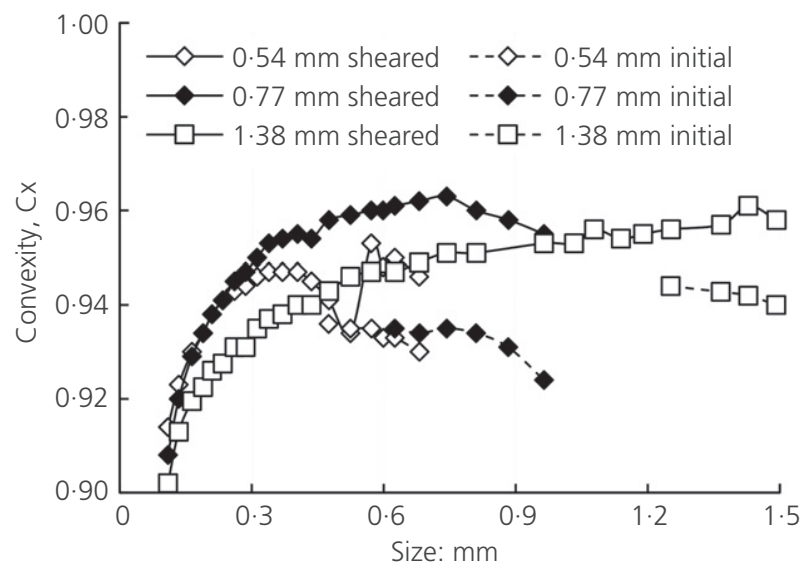

(b)

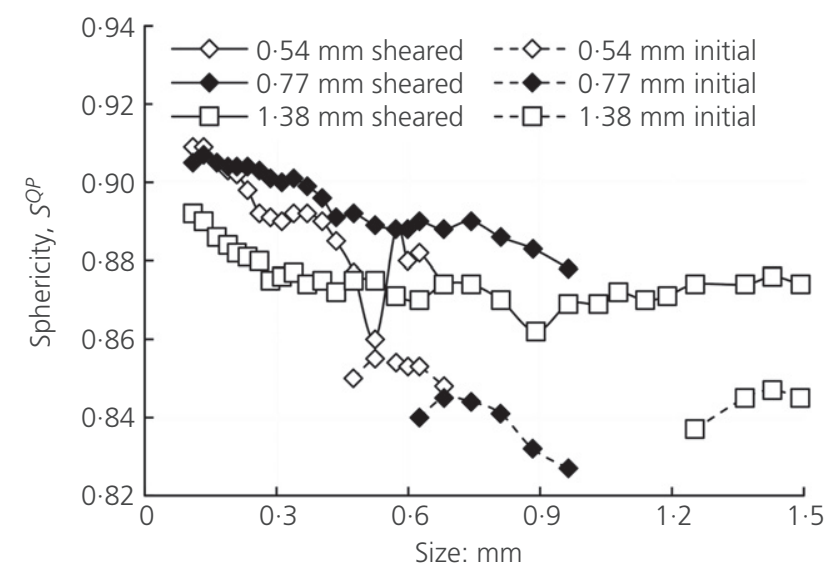

(c)

Fig. 6. Shape factors against the particle size: initial values and values after shearing for $s=2 \mathrm{~m}$ of (a) spect ratio, (b) convexity and (c) sphericity. The values in the legend are the initial $d_{50}$ of the specimens 


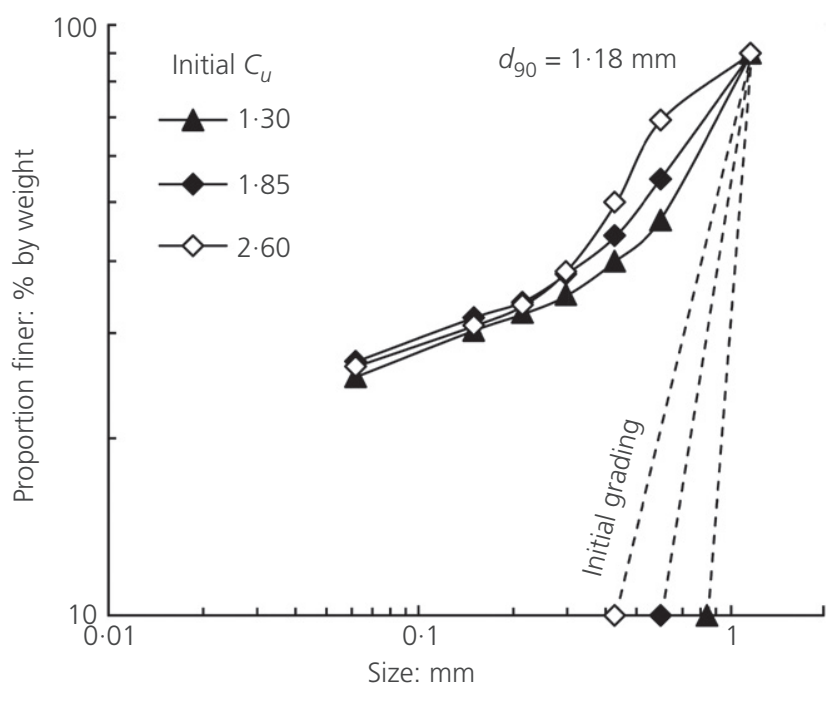

Fig. 7. Grain size distribution of specimens with different initial grading (dashed curves) after shearing for $s=2 \mathrm{~m}$. The specimens had the same initial $d_{90}=1.18 \mathrm{~mm}$, but different $C_{\mathrm{u}}$

exhibit significant differences. Well-graded soils suffered larger (total) breakage than poorly graded soils after the same shearing distance, while the relative breakage and fractal dimension did not vary significantly.

\section{ACKNOWLEDGEMENTS}

This research was supported by the National Basic Research Program of China: the Funds for creative research groups of China (41521002), National Basic Research Program of China (41790443). This research was also supported by the State Key Laboratory of Geo-Hazard Prevention and Geo-environmental Protection of Chengdu University of Technology (SKLGP2013K001), Fundamental Research Funds for the Central Universities (2017QL04) and the Yue Qi Distinguished Scholar Project, China University of Mining and Technology, Beijing.

\section{REFERENCES}

Altuhafi, F. \& Baudet, B. A. (2011). A hypothesis on the relative roles of crushing and abrasion in the mechanical genesis of a glacial sediment. Engng Geol. 120, No. 1-4, 1-9, https://doi.org/10.1016/j.enggeo.2011.03.002.

Altuhafi, F. \& Coop, M. (2011). Changes to particle characteristics associated with the compression of sands. Géotechnique 61, No. 6, 459-471, https://doi.org/10.1680/geot.9.P.114.

Altuhafi, F., Baudet, B. A. \& Sammonds, P. (2010). The mechanics of subglacial sediment: an example of 'transitional behaviour'. Can. Geotech. J. 47, No. 7, 775-790, https://doi.org/10.1139/ T09-136.

Altuhafi, F., O' Sullivan, C. \& Cavarretta, I. (2013). Analysis of an image-based method to quantify the size and shape of sand particles. J. Geotech. Geoenviron. 139, No. 8, 1290-1307, https://doi.org/10.1061/(ASCE)GT.1943-5606.0000855.

Bishop, A. W., Green, G. E., Garge, V. K., Andersen, A. \& Brown, J. D. (1971). A new ring shear apparatus and its application to the measurement of residual strength. Géotechnique 21, No. 93, 273-328, https://doi.org/ 10.1680/geot.1971.21.4.273.

Bolton, M. D. \& McDowell, G. R. (1997). Clastic mechanics. In IUTAM symposium on mechanics of granular and porous materials (eds N. A. Fleck and A. C. F. Cocks), pp. 35-46. Cambridge, UK: Kluwer Academic Publishers.

Caballero, L., Sarocchi, D., Soto, E. \& Borselli, L. (2014). Rheological changes induced by clast fragmentation in debris flows. J. Geophys. Res. Earth Surf. 119, No. 9, 1800-1817, https://doi.org/10.1002/2013JF002942.
Carrubba, P. \& Colonna, P. (2006). Monotonic fast residual strength of clay soils. Ital. Geotech. J. 40, No. 3, 32-51.

Cavarretta, I., Coop, M. \& O' Sullivan, C. (2010). The influence of particle characteristics on the behaviour of coarse grained soils. Géotechnique 60, No. 6, 413-423, https://doi.org/10.1680/ geot.2010.60.6.413.

Cho, G., Dodds, J. \& Santamarina, J. (2006). Particle shape effects on packing density, stiffness, and strength: natural and crushed sands. J. Geotech. Geoenviron. 132, No. 5, 591-602, https://doi.org/10.1061/(ASCE)1090-0241(2006)132:5(591).

Clayton, C. R. I., Xu, M. \& Bloodworth, A. (2006). A laboratory study of the development of earth pressure behind integral bridge abutments. Géotechnique 56, No. 8, 561-571, https://doi. org/10.1680/geot.2006.56.8.561.

Coop, M. R., Sorensen, K. K., Freitas, T. B. \& Georgoutsos, G. (2004). Particle breakage during shearing of a carbonate sand. Géotechnique 54, No. 3, 157-163, https://doi.org/10.1680/geot. 2004.54.3.157.

Cubrinovski, M. \& Ishihara, K. (2002). Maximum and minimum void ratio characteristics of sands. Soils Found. 42, No. 6, 65-78, https://doi.org/10.3208/sandf.42.6_65.

De Blasio, F. V. \& Crosta, G. B. (2015). Fragmentation and boosting of rock falls and rock avalanches. Geophys. Res. Lett. 42, No. 20, 8463-8470, https://doi.org/10.1002/2015GL064723.

Einav, I. (2007a). Breakage mechanics-part I: theory. J. Stat. Mech-Theroy E. 55, No. 6, 1274-1297, https://doi.org/10.1016/ j.jmps.2006.11.003.

Einav, I. (2007b). Breakage mechanics-part II: modelling granular materials. J. Stat. Mech-Theroy E. 55, No. 6, 1298-1320, https://doi.org/10.1016/j.jmps.2006.11.004.

Fonseca, J. \& O'Sullivan, C. (2008). A re-evaluation of the Fourier descriptor approach to quantifying sand particle geometry. 4th international symposium on deformation characteristics of geomaterials Atlanta, Amsterdam, the Netherlands, pp. 687-690. Fairfax, VA, USA: IOS Press.

Gajo, A. \& Muir Wood, D. (1999). Severn-Trent sand: a kinematic-hardening constitutive model: the $q-p$ formulation. Géotechnique 49, No. 5, 595-614, https://doi.org/10.1680/geot. 1999.49.5.595.

Hagerty, M. M., Hite, D. R., Ullrich, C. R. \& Hagerty, D. J. (1993) One-dimensional high-pressure compression of granular media. J. Geotech. Engng 119, No. 1, 1-18, https://doi.org/10. 1061/(ASCE)0733-9410(1993)119:1(1).

Hardin, B. (1985). Crushing of soil particles. J. Geotech. Engng 111 No. 10, 1177-1192, https://doi.org/10.1061/(ASCE)0733-9410 (1985)111:10(1177).

Hooke, R. L. \& Iverson, N. R. (1995). Grain-size distribution in deforming subglacial tills: role of grain fracture. Geology 23, No. 1, 57-60, https://doi.org/10.1130/0091-7613(1995) 023<0057:GSDIDS>2.3.CO;2.

Hu, W., Scaringi, G., Xu, Q., Pei, Z., van Asch, T. W. J. \& Hicher, P. Y. (2017a). Sensitivity of the initiation and runout of flowslides in loose granular deposits to the content of small particles: an insight from flume tests. Engng Geol 231, 34-44, https://doi.org/10.1016/j.enggeo.2017.10.001.

Hu, W., Wang, G., Xu, Q., Scaringi, G., McSaveney, M. \& Hicher, P. Y. (2017b). Shear resistance variations in experimentally sheared mudstone granules: a possible shear-thinning and thixotropic mechanism. Geophys. Res. Lett. 44, No. 21, 11040-11050, https://doi.org/10.1002/2017GL075261.

Huang, C. \& Bradford, J. M. (1992). Applications of a laser scanner to quantify soil microtopography. Soil Sci. Soc. Am. J. 56, No. 1, 14-21, https://doi.org/10.2136/sssaj1992. $03615995005600010002 x$.

Krumbein, W. C. \& Sloss, L. L. (1951). Stratigraphy and sedimentation. Soil Sci. Soc. Am. J. 71, No. 5, 401, https://doi.org/ 10.1086/625952.

Mandelbrot, B. B. (1982). The fractal geometry of nature. San Francisco, CA, USA: W. H. Freeman, ISBN: 0-7167-1186-9.

McDowell, G. R. (2002). On the yielding and plastic compression of sand. Soils Found. 42, No. 1, 139-145, https://doi.org/10.3208/ sandf.42.139.

McDowell, G. R. \& Amon, A. (2000). The application of Weibull statistics to the fracture of soil particles. Soils Found. 40, No. 5, $133-141$. 
McDowell, G. R. \& De Bono, J. P. (2013). On the micro mechanics of one-dimensional normal compression. Géotechnique $\mathbf{6 3}$, No. 11, 895-908, https://doi.org/10.1680/geot.12.P.041.

McDowell, G. R., Bolton, M. D. \& Robertson, D. (1996). The fractal crushing of granular materials. J. Stat. Mech, Theor. Exp. 44, No. 12, 2079-2101, https://doi.org/10.1016/S0022-5096(96) 00058-0.

Miao, G. \& Airey, D. W. (2013). Breakage and ultimate states for a carbonate sand. Géotechnique 63, No. 14, 1221-1229, https://doi.org/10.1680/geot.12.P.111.

Miao, G. \& Airey, D. W. (2015). Repetitive compression tests on a carbonate sand. In Bifurcation and degradation of geomaterials in the new millennium. Springer series in geomechanics and geoengineering (eds K. T. Chau and J. Zhao), pp. 369-374. Cham, Switzerland: Springer.

Miura, N. \& O-Hara, S. (1979). Particle-crushing of a decomposed granite soil under shear stresses. Soils Found. 19, No. 3, 1-14, https://doi.org/10.3208/sandf1972.19.3_1.

Muir Wood, D. (2007). The magic of sands. Can. Geotech. J. 44, No. 11, 1329-1350, https://doi.org/10.1139/T07-060.

Nakata, Y., Kato, Y., Hyodo, M. \& Murata, H. (1999). Single particle crushing properties of geomaterials. In Proceedings of the 2 nd international symposium on pre-failure deformation characteristics of geomaterials, Torino, Italy (eds M. Jamiolkowski, R. Lancellotta and D. Lo Presti), pp. 221-228. Rotterdam, the Netherlands: Balkema.

Nakata, Y., Hyodo, M., Hyde, F. L., Kato, Y. \& Murata, H. (2001). Microscopic particle crushing of sand subjected to high pressure one-dimensional compression. Soils Found. 41, No. 1, 62-82.

Okada, Y., Sassa, K. \& Fukuoka, H. (2004). Excess pore pressure and grain crushing of sands by means of undrained and naturally drained ring-shear tests. Engng Geol. 75, No. 3-4, 325-343.

Perfect, E., Rasiah, V. \& Kay, B. D. (1992). Fractal dimensions of soil aggregate size distributions calculated by number and mass. Soil Sci. Soc. Am. J. 56, No. 5, 1407-1409, https://doi.org/ 10.2136/sssaj1992.03615995005600050012x.

Rasiah, V., Kay, B. D. \& Perfect, E. (1993). New mass-based model for estimating fractal dimensions of soil aggregates. Soil Sci. Soc. Am. J. 57, No. 4, 891-895, https://doi.org/10.2136/sssaj1993. $03615995005700040002 x$.

Rousé, P. C., Fannin, R. J. \& Shuttle, D. A. (2008). Influence of roundness on the void ratio and strength of uniform sand. Géotechnique 58, No. 3, 227-231, https://doi.org/10.1680/geot. 2008.58.3.227.

Saito, R., Fukuoka, H. \& Sassa, K. (2006). Experimental study on the rate effect on the shear strength. In Disaster mitigation of debris flows, slope failures and landslides (eds F. Berger and L. Dorren), pp. 421-427. Tokyo, Japan: Universal Academy Press, Inc.

Saito, R., Sassa, K. \& Fukuoka, H. (2007). Effects of shear rate on the internal friction angle of silica sand and bentonite mixture samples. J. Jpn. Landslide Soc. 44, No. 1, 33-38 (in Japanese).

Santamarina, J. C. \& Cho, G. C. (2004). Soil behaviour: the role of particle shape. Proceedings of the Skempton Conference, London, pp. 1-14. London, UK: Thomas Telford.

Scaringi, G., Telesca, G., Vassallo, R. \& Di Maio, C. (2013). Resistenza residua a taglio di un-argilla illitica: influenza della velocità di scorrimento, della composizione del fluido interstiziale, della modalità di taglio. Incontro Annuale dei Ricercatori di Geotecnica 2013, IARG 2013, Perugia, Italy, p. 6, ISBN: 978 8890642135 (in Italian).

Scaringi, G., Hu, W., Xu, Q. \& Huang, R. (2017). Shear-rate-dependent behavior of clayey bi-material interfaces at landslide stress levels. Geophys. Res Lett. 45, https://doi. org/10.1002/2017GL076214.

Taboada, A. \& Estrada, N. (2009). Rock-and-soil avalanches: theory and simulation. J. Geophys. Res. 114, No. F4, F03004, https://doi.org/10.1029/2008JF001072.

Tika, T. E., Vaughan, P. R. \& Lemos, L. J. L. (1996). Fast shearing of pre-existing shear zones in soil. Géotechnique 46, No. 2, 197-233, https://doi.org/10.1680/geot.1996.46.2.197.

Tsoungui, O., Vallet, D. \& Charmet, J. C. (1999). Numerical model of crushing of grains inside two-dimensional granular materials. Powder Technol. 105, No. 1-3, 190-198.

Turcotte, D. L. (1986). Fractals and fragmentation. J. Geophys. Res. 91, No. B2, 1921-1926, https://doi.org/10.1029/ JB091iB02p01921.

Wadell, H. (1932). Volume, shape, and roundness of rock particles. J. Geol. 40, No. 5, 443-451, https://doi.org/10.1086/623964.

Yao, Y. P., Yamamoto, H. \& Wang, N. D. (2008). Constitutive model considering sand crushing. Soils Found. 48, No. 4, 603-608.

Yao, Y. P., Hou, W. \& Zhou, A. N. (2009). UH model: three-dimensional unified hardening model for overconsolidated clays. Géotechnique 59, No. 5, 451-469, https://doi.org/10.1680/ geot.2007.00029.

Zhang, X. \& Baudet, B. A. (2013). Particle breakage in gap-graded soil. Géotech. Lett. 3, No. 2, 72-77, https://doi.org/10.1680/ geolett.13.00022.

Zhang, X. \& Baudet, B. A. (2014). The multi-fractal nature of soil particle size distribution. In Geomechanics from micro to macro (eds K. Soga, K. Kumar, G. Biscontin and M. Kuo), pp. 1183-1188. London, UK: Taylor \& Francis Group. 